\title{
Evaluation of small bowel motion and feasibility of using the peritoneal space to replace bowel loops for dose constraints during intensity-modulated radiotherapy for rectal cancer
}

\author{
Siyuan $\mathrm{Li}^{1,2+}$, Yanping Gong ${ }^{3+}$, Yongqiang Yang ${ }^{1}$, Qi Guo ${ }^{1}$, Jianjun Qian ${ }^{1 *}$ and Ye Tian ${ }^{1 *}$
}

\begin{abstract}
Background: The goal of this study was to assess small bowel motion and explore the feasibility of using peritoneal space (PS) to replace bowel loops (BL) via the dose constraint method to spare the small bowel during intensity-modulated radiotherapy (IMRT) for rectal cancer.

Methods: A total of 24 patients with rectal cancer who underwent adjuvant or neoadjuvant radiotherapy were selected. Weekly repeat CT scans from pre-treatment to the fourth week of treatment were acquired and defined as Plan, $1 \mathrm{~W}, 2 \mathrm{~W}, 3 \mathrm{~W}$, and $4 \mathrm{~W}$. The 4 weekly CT scans were co-registered to the Plan CT, BL and PS contours were delineated in all of the scans, an IMRT plan was designed on Plan CT using PS constraint method, and then copied to the 4 weekly CT scans. The dose-volume, normal tissue complication probability (NTCP) of the small bowel and their variations during treatment were evaluated.

Results: Overall, 109 sets of CT scans from 24 patients were acquired, and 109 plans were designed and copied. The BL and PS volumes were $250.3 \mathrm{cc}$ and $1339.3 \mathrm{cc}$. The $\mathrm{V}_{15}$ of BL and PS based plan of pre-treatment were 182.6 $\mathrm{cc}$ and $919.0 \mathrm{cc}$, the shift\% of them were 28.9 and $11.3 \%$ during treatment $(p=0.000)$, which was less in the prone position than in the supine position $(25.2 \%$ vs $32.1 \%, p=0.000 ; 9.9 \%$ vs $14.9 \%, p=0.000)$. The NTCP and NTCPA based plan of pre-treatment were 2.0 and $59.2 \%$, the shift\% during treatment were 46.1 and $14.0 \%$ respectively. Majority of BL's $D_{\max }$ and $V_{15}$ were meet the safety standard during treatment using PS dose limit method except 3 times (3/109) of $V_{15}$ and 5 times of $D_{\max }(5 / 109)$.

\footnotetext{
* Correspondence: qianjianjun0628@aliyun.com; dryetian@126.com

†Siyuan Li and Yanping Gong are contributed equally to this study.

'Department of Radiotherapy \& Oncology, Second Affiliated Hospital of

Soochow University, Institute of Radiotherapy and Oncology, Soochow

University, Suzhou Key Laboratory for Radiation Oncology, Suzhou 215004,

China

Full list of author information is available at the end of the article
}

(c) The Author(s). 2020 Open Access This article is licensed under a Creative Commons Attribution 4.0 International License, which permits use, sharing, adaptation, distribution and reproduction in any medium or format, as long as you give appropriate credit to the original author(s) and the source, provide a link to the Creative Commons licence, and indicate if changes were made. The images or other third party material in this article are included in the article's Creative Commons licence, unless indicated otherwise in a credit line to the material. If material is not included in the article's Creative Commons licence and your intended use is not permitted by statutory regulation or exceeds the permitted use, you will need to obtain permission directly from the copyright holder. To view a copy of this licence, visit http://creativecommons.org/licenses/by/4.0/ The Creative Commons Public Domain Dedication waiver (http://creativecommons.org/publicdomain/zero/1.0/) applies to the data made available in this article, unless otherwise stated in a credit line to the data. 
(Continued from previous page)

Conclusions: This study indicated that small bowel motion may lead to uncertainties in its dose volume and NTCP evaluation during IMRT for rectal cancer. The BL movements were significantly greater than PS, and the prone position was significantly less than the supine position. It is feasibility of using PS to replace BL to spare the small bowel, $V_{15}<830 \mathrm{cc}$ is the dose constraint standard.

Keywords: Rectal cancer, Intensity modulated radiotherapy (IMRT), Small bowel, Bowel loops, Peritoneal space, Normal tissue complication probability (NTCP)

\section{Background}

Radiochemotherapy is a widely accepted treatment mode in patients with locally advanced rectal cancer. It can result in a significant reduction in the local recurrence rate by up to $30 \%$ and improve the 5 -year disease-free survival rate [1-6].

Although radiochemotherapy can help cure many rectal cancer survivors, acute and chronic intestinal side effects (12-50\%) such as diarrhoea, faecal incontinence, and late small bowel obstructions have attracted increasing attention because they may affect patients' quality of life and even interrupt treatment [7-10]. Studies have shown that the irradiated small bowel volume is closely related to toxicity caused by radiotherapy, so reducing its irradiated volume is the key approach to effectively prevent and reduce toxicity $[11,12]$. Although intensitymodulated radiation therapy (IMRT) reduces the risk of radiation-induced toxicity, toxicity remains a significant concern.

In 2010, the Quantitative Analysis of Normal Tissue Effects in the Clinic (QUANTEC) review provided the available dose volume data for small bowel toxicity. Acute small bowel injury has been described with a threshold dose of grade 3 or greater toxicity when $120 \mathrm{cc}$ volume of individually contoured bowel loops (BLs) receive $\geq 15$ Gy or when $195 \mathrm{cc}$ of the contoured peritoneal space (PS) receives $\geq 45$ Gy $[13,14]$. These are commonly incorporated into radiotherapy protocols in clinical practise.

Contouring the PS and BL are two primary ways to evaluate the small bowel dose volume $[15,16]$. However, the small bowel is always in motion and there may be uncertainties in dose volume evaluations. The characteristics of narrow high dose distribution in IMRT technology will further increase this uncertainty.

PS contouring has the advantages of accuracy, convenience, and repeatability compared with BL contouring. This volume can allow the small bowel to lie at any point during treatment and can mitigate the impact of small bowel movements. The scope of this study was to quantify the impact of small bowel movements on the dose volume and normal tissue complication probability (NTCP) estimates and feasibility of using PS replace BL for dose constraints to provide an optimised method of sparing the small bowel during IMRT for rectal cancer.

\section{Methods \\ Patients}

The ethics board of the hospital approved the present study, and all of the investigations were conducted in accordance with the relevant guidelines and regulations. From March 2014 to March 2016, 24 patients with rectal cancer who underwent adjuvant or neoadjuvant radiotherapy were selected. The patient characteristics are summarised in Table 1.

Table 1 Patient characteristics

\begin{tabular}{|c|c|c|}
\hline Variable & $n$ & $\%$ \\
\hline \multicolumn{3}{|l|}{ Gender } \\
\hline Male & 15 & 62.5 \\
\hline Female & 9 & 37.5 \\
\hline \multicolumn{3}{|l|}{ Age (y) } \\
\hline Range & $39-77$ & / \\
\hline Median & 58.5 & / \\
\hline \multicolumn{3}{|l|}{ T stage } \\
\hline $\mathrm{T} 2$ & 4 & 16.7 \\
\hline T3 & 18 & 75.0 \\
\hline T4 & 2 & 8.3 \\
\hline \multicolumn{3}{|l|}{ N stage } \\
\hline NO & 8 & 33.3 \\
\hline $\mathrm{N} 1$ & 13 & 54.2 \\
\hline N2 & 3 & 12.5 \\
\hline \multicolumn{3}{|l|}{ Clinical stage } \\
\hline$\|$ & 10 & 41.7 \\
\hline III & 14 & 58.3 \\
\hline \multicolumn{3}{|c|}{ Treatment position } \\
\hline Supine & 12 & 50.0 \\
\hline Prone & 12 & 50.0 \\
\hline \multicolumn{3}{|l|}{ Radiotherapy } \\
\hline Adjuvant & 16 & 66.7 \\
\hline Neoadjuvant & 8 & 33.3 \\
\hline
\end{tabular}




\section{Planning CT}

CT scans (3 mm thick slices) of the patients' whole abdomen and pelvis were obtained with the treatment position on a Siemens Emotion-Duo CT simulator. Standard commercial immobilisation devices were applied. A carbon fibre frame and thermoplastic mask fixation (Pelvicast system, Orfit, Wijnegem, Belgium) was used. The patients were in the supine position with a pillow under their heads. Their knees and ankles were supported with vacuum cushions, and their arms resting on their chests. In the prone position, a belly board (Civco Medical Solutions, Coralville, IA, USA) was applied to allow the abdomen to extend into its aperture. The patients were instructed to empty the bladder an hour before CT simulation. Gastrografin solution (600 $\mathrm{mL}$ ) was administered orally an hour before scanning to better visualise the small bowel for delineation. CT scans were subsequently imported into the treatment planning system (Pinnacle 9.0, Philips Radiation Oncology, Fitchburg, MA. USA) for target delineation and treatment planning design. After the plan was confirmed, the patients were treated at the Medical Synergy Accelerator (Elekta Synergy, Elekta Oncology Systems, Crawley, UK), and when treatment they were required to keep their bladder moderately filled similar to simulation. CT images were obtained and defined as $1 \mathrm{~W}, 2 \mathrm{~W}, 3 \mathrm{~W}$, and 4 $\mathrm{W}$, respectively, on the Friday of weeks 1-4 during treatment under the same scanning conditions. Subsequently, the 4 weekly CT scans were automatically co-registered to the Plan CT respectively based on pelvic bone anatomy, algorithm of Normalized Mutual Information in treatment planning system was used.

\section{Delineation of PS and BL}

Per the delineation methods of small bowel from RTOG [17] and Robyn B [16], BL and PS were delineated for each patient's group of CT images. BL was delineated along the bowel loop's outer surface based on the contrast effect of Gastrografin solution and excluding the colon. The upper boundary was $1 \mathrm{~cm}$ above the superior level of the planning target volume (PTV), and the lower boundary was delineation of the small bowel until it ended. For the PS, the anterior and bilateral boundaries were the inner surface of the abdominal muscles, the posterior boundary was the vertebral body, sacrum, or sigmoid colon. The upper boundary was 1 $\mathrm{cm}$ above the superior PTV level. The lower boundary was parallel to the inferior sigmoid colon level. The PS included the small bowel and colon, but did not include the bladder, ovary, and uterus. A window width of 600 and window level of 40 were selected for delineation of the BL and PS and were completed by the same senior attending physician.
Target volume definition and treatment planning design The target volume was delineated per the RTOG and NCCN guidelines $[18,19]$. The clinical target volume (CTV) included the lymphatic drainage area of the perirectal lymph nodes, presacral lymph nodes, and internal iliac lymph nodes, and some patients' external iliac lymph nodes were included. A margin of $1 \mathrm{~cm}$ in the cranial-caudal direction and $0.5 \mathrm{~cm}$ in the anteriorposterior and lateral directions was given to the CTV to form the PTV. The prescription was $50 \mathrm{~Gy}$ in 25 fractions to the PTV. In the Pinnacle 9.0 treatment planning system, 7 field IMRT plans used the PS $\left(\mathrm{V}_{15}<830 \mathrm{cc}\right)$ dose constraints were designed [16]. The plans used a 6 MV X-ray CC convolution algorithm and a $0.3 \mathrm{~cm}$ computational grid. An Elekta Synergy accelerator and 40 pairs of MLCs were selected. Dose constraints of $\mathrm{V}_{40}<$ $50 \%$ and $\mathrm{V}_{50}<5 \%$ were used for the bladder and bilateral femoral head respectively. The target dose coverage required more than $95 \%$ of the PTV covered by $100 \%$ of the prescription dose and a maximum dose $\left(D_{\max }\right)<54$ Gy inside and outside the PTV. Subsequently, the IMRT plans from the Plan CT were copied to the 1-4 W CT images which had co-registered to the Plan CT.

\section{Evaluation of small bowel dose volume}

The absolute irradiated volume (cc) of the small bowel was described by its volume exposed to 5-50 Gy with 5 Gy intervals. Each patient's small bowel volume (or irradiated volume) was expressed by the mean value over their CT images. All of the patients' small bowel volumes (or irradiated volumes) during treatment were expressed as their median volume values.

\section{Evaluation of small bowel motion}

The shift\% was used to describe the small bowel movements, and shift $\%=\mathrm{SD} /$ mean [20]. The SD and mean were the standard deviation and mean of the small bowel volume (or irradiated volume) from all of the CT images. The variations among the patients were expressed by their median values. A larger shift $\%$ signified greater motion of the small bowel during treatment.

\section{NTCP prediction of small bowels}

The Lyman-Kutcher-Burman (LKB) calculation module in Pinnacle 9.0 was used to predict chronic complications of the small bowel (called $\mathrm{NTCP}_{\mathrm{C}}$ ) [21-23]. The $\mathrm{n}$ (volume factor), $\mathrm{m}$ (slope of dose response curve), and $\mathrm{TD}_{50}$ (mean dose of $50 \%$ complication probability) parameters were set to $0.15,0.16$, and $55 \mathrm{~Gy}$, respectively [24]. The complications were defined as small bowel obstructions, perforations, or fistulas. Logistic formula $\mathrm{NTCP}=\left(1+\left(\mathrm{V}_{50} / \mathrm{V}\right)^{\mathrm{k}}\right)^{-1}$ was used to calculate the acute toxicity of the small bowel based on its $\mathrm{V}_{15}$ (called $\mathrm{NTCP}_{\mathrm{A}}$ ), where $\mathrm{V}_{50}$ and $\mathrm{k}$ were $130 \mathrm{cc}$ and 1.1, 
respectively [25]. Each patient's NTCP was expressed by the mean value over their all of the CT images. The NTCP of all of the patients during treatment was expressed by their median values. The shift\% here was used to describe the NTCP variations during treatment, and $\mathrm{shift} \%=\mathrm{SD} /$ mean .

\section{Safety assessment of small bowel during treatment}

$\mathrm{V}_{15}<275 \mathrm{cc}$ from Robyn $\mathrm{B}$ et al. [16] and $\mathrm{D}_{\max } \leq 54 \mathrm{~Gy}$ were used as the criteria for safety evaluation of the small bowel during treatment. The small bowel was at risk when the value exceeded these criteria.

\section{Statistical analysis}

SPSS 19.0 software was used for the data analysis. Sigma Plot 10.0 and Microsoft Excel 2007 were used for figure plotting. A paired sample t-test was used to compare the differences between the two groups' data, and their correlation was analysed via Pearson's correlation coefficient. A two-tailed value of $p<0.05$ was considered statistically significant.

\section{Results}

PS and BL contours and treatment plans

Figure 1 shows an example of a rectal cancer patient's PS and BL contours and dose distribution based on

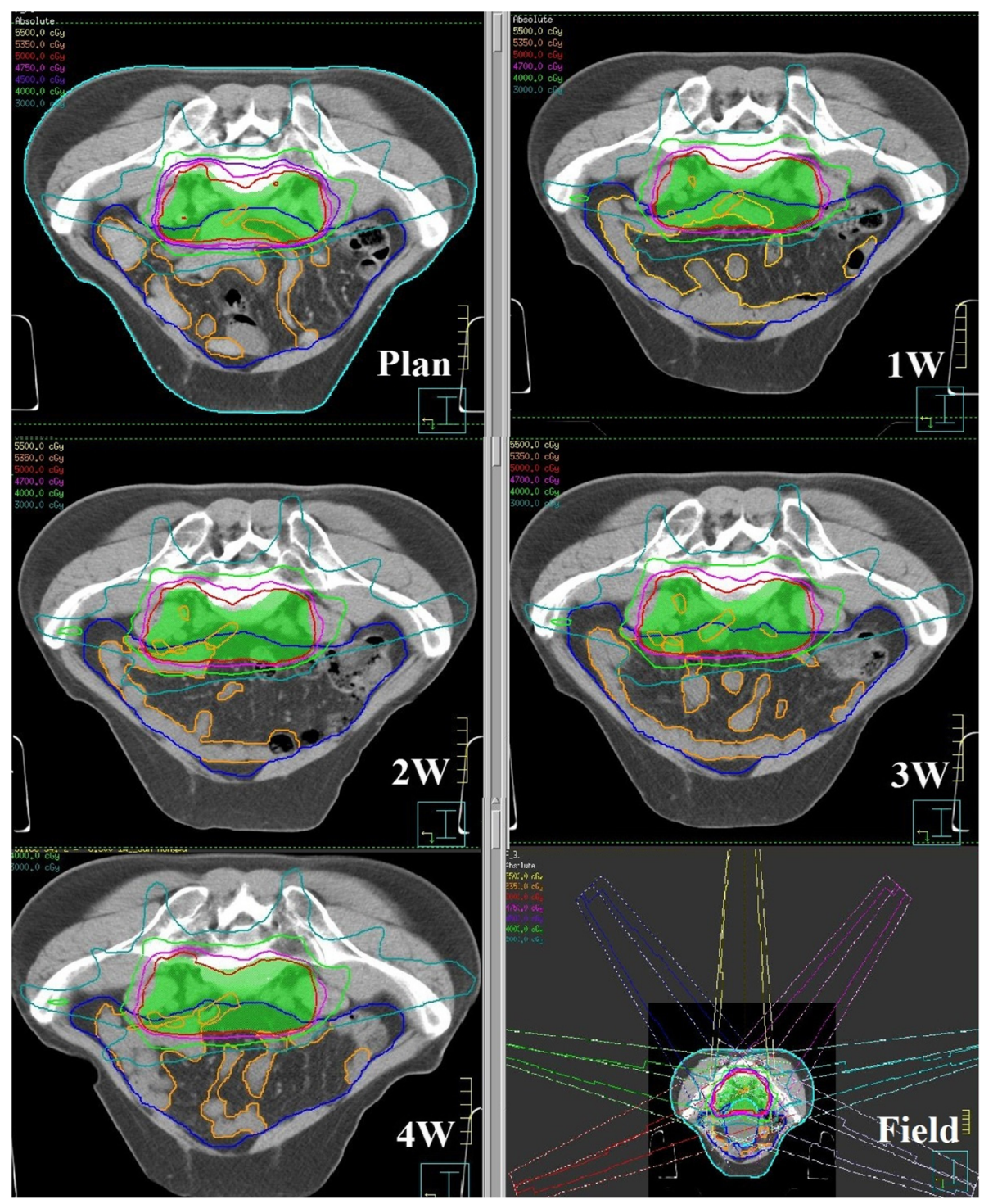

Fig. 1 An example of a rectal cancer patient's PS and BL contours and dose distribution based on different CT scans during treatment. The green, blue, and orange contours represent PTV, PS, and BL, respectively. The innermost and outermost dose lines are 50 Gy and 30 Gy, respectively. Picture Plan, 1 W, 2 W, 3 W, 4 W show the variations of PS and BL's contours and dose distribution during treatment, picture Field show the radiotherapy field setup 
different CT scans during treatment. A total of 109 sets of CT images were obtained for 24 patients, including 24 sets of Plan, $2 \mathrm{~W}$, and $3 \mathrm{~W}$ scans, 14 sets of $1 \mathrm{~W}$ scans, and 23 sets of $4 \mathrm{~W}$ scans. Overall, 218 contours containing the PS and BL were delineated for each patient. The median PS volume was $1339.3 \mathrm{cc}$ (537.3$2121.7 \mathrm{cc}$ ) and the median $\mathrm{BL}$ volume was $250.3 \mathrm{cc}$ $(81.0-590.8 \mathrm{cc})$ in all of the patients. A total of 24 sets of IMRT plans were designed based on Plan CT (109 sets of plans obtained after the plans copied to 1-4 W CT scans). In plan of pre-treatment, the median $\mathrm{V}_{15}$ of the PS was $919.0 \mathrm{cc}(493.4-1324.6 \mathrm{cc})$, and 13 sets $(13 / 24)$ were $\mathrm{V}_{15}>830 \mathrm{cc}$, all of the other dose constraints were met (the $\mathrm{V}_{15}$ of $\mathrm{BL}$ was $\leqq 275.71 \mathrm{cc}$ ).

\section{Evaluation of small bowel motion}

The shift\% of the BL and PS volumes was $28.5 \%$ (11.8$80.8 \%)$ and $9.8 \%(2.8-38.7 \%)$, respectively. The movement of BL was significantly larger than PS $(p=0.000)$. As shown in Fig. 2 and Table 2 and 3, the shift $\%$ of dose-volume $\left(\mathrm{V}_{5-50}\right)$ from $28.9-55.0 \%$ in BL was significantly larger than the PS of 7.9-23.8\% (top picture of Fig. 2). The shift $\%$ of the BL and PS's $\mathrm{V}_{15}$ were $28.9 \%$ $(4.8-72.2 \%)$ and $11.3 \%(3.2-42.8 \%)(p=0.000)$ respectively, and the shift $\%$ of $\mathrm{V}_{30}$ were $35.8 \%(3.8-88.8 \%)$ and $14.4 \%(4.2-47.3 \%)$ respectively $(p=0.000)$. The shift $\%$ of the BL and PS's $\mathrm{V}_{15}$ in the prone position was lower than in the supine position $(25.2 \%$ vs $32.1 \%, p=0.000$; $9.9 \%$ vs $14.9 \%, p=0.000)$. As shown in Fig. 3, there was
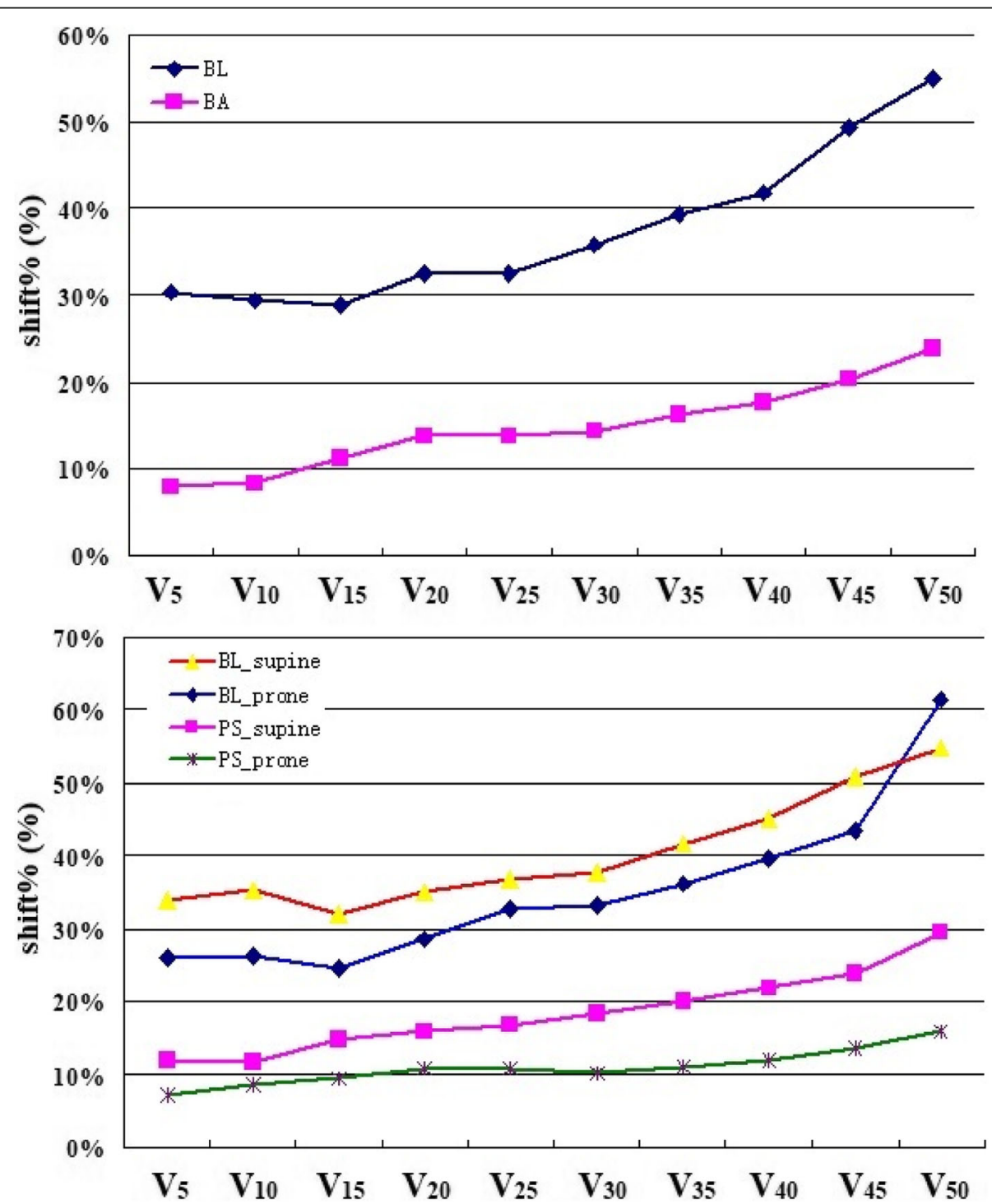

Fig. 2 The shift\% of the BL and PS' dose-volume during treatment. The top picture show the difference of shift\% between the BL and PS, dark blue and purple lines represent BL and PS respectively. The bottom picture show the difference of shift\% between the supine and prone position, the red and dark blue lines represent shift\% of BL in supine and prone position respectively, the purple and green lines represent shift\% of PS in supine and prone position respectively 
Table 2 The dose-volume and NTCP of BL and their shift\% during treatment

\begin{tabular}{|c|c|c|c|c|c|c|c|c|c|c|c|c|}
\hline Variable & Plan & $1 \mathrm{~W}$ & $P_{1}$ & $2 W$ & $P_{2}$ & $3 W$ & $P_{3}$ & $4 W$ & $P_{4}$ & Mean & SD & shift $\%$ \\
\hline$V_{5}(c c)$ & 288.9 & 356.3 & 0.897 & 210.0 & 0.009 & 263.8 & 0.169 & 224.0 & 0.007 & 248.7 & 75.5 & $30.4 \%$ \\
\hline$V_{10}(c c)$ & 244.0 & 270.2 & 0.902 & 187.4 & 0.012 & 223.8 & 0.441 & 197.1 & 0.015 & 223.4 & 65.8 & $29.4 \%$ \\
\hline$V_{15}(\mathrm{cc})$ & 182.6 & 219.0 & 0.731 & 144.6 & 0.042 & 181.5 & 0.887 & 167.3 & 0.023 & 170.1 & 49.1 & $28.9 \%$ \\
\hline $\mathrm{V}_{20}(\mathrm{cc})$ & 152.8 & 173.5 & 0.985 & 120.4 & 0.058 & 166.0 & 0.639 & 125.3 & 0.036 & 139.2 & 45.3 & $32.6 \%$ \\
\hline$V_{25}(\mathrm{cc})$ & 125.7 & 139.7 & 0.858 & 91.1 & 0.126 & 148.3 & 0.924 & 105.2 & 0.084 & 112.2 & 36.5 & $32.6 \%$ \\
\hline $\mathrm{V}_{30}(\mathrm{cc})$ & 99.9 & 116.1 & 0.611 & 73.1 & 0.277 & 111.1 & 0.641 & 81.0 & 0.171 & 82.3 & 29.5 & $35.8 \%$ \\
\hline$V_{35}(c c)$ & 79.2 & 98.9 & 0.439 & 55.5 & 0.45 & 85.4 & 0.405 & 60.8 & 0.185 & 63.9 & 25.1 & $39.3 \%$ \\
\hline $\mathrm{V}_{40}(\mathrm{cc})$ & 61.1 & 72.0 & 0.339 & 42.3 & 0.795 & 65.3 & 0.199 & 48.9 & 0.260 & 50.5 & 21.1 & $41.8 \%$ \\
\hline$V_{45}(c c)$ & 42.3 & 47.3 & 0.215 & 32.3 & 0.743 & 48.3 & 0.152 & 34.1 & 0.368 & 37.2 & 18.4 & $49.4 \%$ \\
\hline $\mathrm{V}_{50}(\mathrm{cc})$ & 17.8 & 23.2 & 0.088 & 19.2 & 0.131 & 22.1 & 0.028 & 18.5 & 0.539 & 21.6 & 11.9 & $55.0 \%$ \\
\hline $\mathrm{NTCP}_{\mathrm{A}}(\%)$ & 59.2 & 63.9 & 0.958 & 52.9 & 0.046 & 59.1 & 0.891 & 56.9 & 0.017 & 56.5 & 7.9 & $14.0 \%$ \\
\hline $\mathrm{NTCP}_{c}(\%)$ & 2.0 & 2.0 & 0.110 & 3.0 & 0.034 & 4.0 & 0.007 & 3.0 & 0.323 & 2.8 & 1.3 & $46.1 \%$ \\
\hline
\end{tabular}

The $P_{1}, P_{2}, P_{3}$, and $P_{4}$ represent the comparison between the $1-4 \mathrm{~W}$ and Plan respectively

a significant correlation of $\mathrm{V}_{15}$ between the PS and $\mathrm{BL}$ during tratmnt, $\mathrm{R}=0.455, p=0.000$.

\section{NTCP of small bowels}

As shown in Table $2(\mathrm{BL})$, the $\mathrm{NTCP}_{\mathrm{C}}$ and $\mathrm{NTCP}_{\mathrm{A}}$ based plan of pre-treatment were 2.0 and $59.2 \%$, the shift $\%$ during treatment were 46.1 and $14.0 \%$ respectively. The difference of $\mathrm{NTCP}_{\mathrm{A}}$ in $2 \mathrm{~W}$ and $4 \mathrm{~W}$, and difference of $\mathrm{NTCP}_{\mathrm{C}}$ in $2-3 \mathrm{~W}$ were significant compared with the plan pre-treatment $(p<0.05)$. As shown in Table 4, NTCP in supine patients were mildly larger than in prone patients, $\mathrm{NTCP}_{\mathrm{C}} 4.9 \%$ vs $2.3 \%(p=0.055)$ and $\mathrm{NTCP}_{\mathrm{A}} 58.3 \%$ vs $55.7 \%(p=0.109)$.

\section{Safety assessment of small bowels during treatment}

As shown in Fig. 4, $\mathrm{V}_{15}$ of the small bowel exceeded 275 cc 3 times (3/109) during treatment, with a maximum of $311.3 \mathrm{cc}$ (over 13.18\%). $\mathrm{D}_{\max }$ of the small bowel > 54 Gy 5 times, and the maximum value was $54.3 \mathrm{~Gy}$.

\section{Discussion}

Because the small bowel is a radiosensitive organ, acute and chronic side effects may occur during rectal cancer radiotherapy. The side effects can be reduced by limiting the dose volume. However, evaluating the small bowel dose volume can be challenging. Characteristics of small bowel movement may weaken the dose-limiting function. The small bowel loops do not remain in the same positions at all times. They experience both oscillating displacements of the wall due to peristalsis and large amplitude shifts due to changes in content. The frequency of peristalsis can reach 8-11 times per minute, and it can combine into complex forms of motion at different times and spaces [26]. Small bowel movements have to be taken into account when evaluating the dose volume by contouring the $\mathrm{BL}$, while the peritoneal space can account for any potential region that may be occupied by the small bowel and covering its movements, so it

Table 3 The dose-volume and its shift\% of PS during treatment

\begin{tabular}{|c|c|c|c|c|c|c|c|c|c|c|c|c|}
\hline Variable & plan & $1 \mathrm{~W}$ & $P_{1}$ & $2 W$ & $P_{2}$ & $3 W$ & $P_{3}$ & $4 W$ & $P_{4}$ & Mean & SD & shift $\%$ \\
\hline$V_{5}(c c)$ & 1222.1 & 1444.7 & 0.147 & 1319.4 & 0.010 & 1359.5 & 0.083 & 1344.9 & 0.334 & 1328.6 & 105.1 & $7.9 \%$ \\
\hline $\mathrm{V}_{10}(\mathrm{cc})$ & 1094.8 & 1319.9 & 0.054 & 1222.4 & 0.741 & 1104.6 & 0.921 & 1169.6 & 0.824 & 1217.8 & 101.9 & $8.4 \%$ \\
\hline $\mathrm{V}_{15}(\mathrm{cc})$ & 919.0 & 1091.4 & 0.143 & 1098.1 & 0.015 & 1075.1 & 0.081 & 1082.1 & 0.351 & 1000.4 & 113.0 & $11.3 \%$ \\
\hline $\mathrm{V}_{20}(\mathrm{cc})$ & 796.8 & 981.0 & 0.071 & 949.9 & 0.015 & 974.5 & 0.003 & 956.3 & 0.103 & 910.5 & 125.0 & $13.7 \%$ \\
\hline $\mathrm{V}_{25}(\mathrm{cc})$ & 695.7 & 845.8 & 0.085 & 814.8 & 0.010 & 850.8 & 0.205 & 716.6 & 0.944 & 799.9 & 109.5 & $13.7 \%$ \\
\hline$V_{30}(c c)$ & 576.2 & 738.3 & 0.325 & 702.1 & 0.007 & 692.9 & 0.097 & 655.4 & 0.787 & 691.6 & 99.6 & $14.4 \%$ \\
\hline$V_{35}(c c)$ & 465.5 & 629.1 & 0.142 & 589.8 & 0.007 & 595.8 & 0.088 & 495.7 & 0.827 & 566.3 & 91.8 & $16.2 \%$ \\
\hline $\mathrm{V}_{40}(\mathrm{cc})$ & 383.1 & 509.5 & 0.179 & 442.5 & 0.784 & 525.2 & 0.001 & 392.4 & 0.945 & 472.8 & 83.5 & $17.7 \%$ \\
\hline$V_{45}(c c)$ & 301.2 & 419.7 & 0.164 & 408.7 & 0.008 & 458.8 & 0.274 & 397.5 & 0.422 & 375.9 & 76.6 & $20.4 \%$ \\
\hline$V_{50}(c c)$ & 201.3 & 280.4 & 0.273 & 292.6 & 0.012 & 281.0 & 0.059 & 278.5 & 0.435 & 276.5 & 65.9 & $23.8 \%$ \\
\hline
\end{tabular}

The $P_{1}, P_{2}, P_{3}$ and $P_{4}$ represent the comparison between the 1-4 W and Plan respectively 


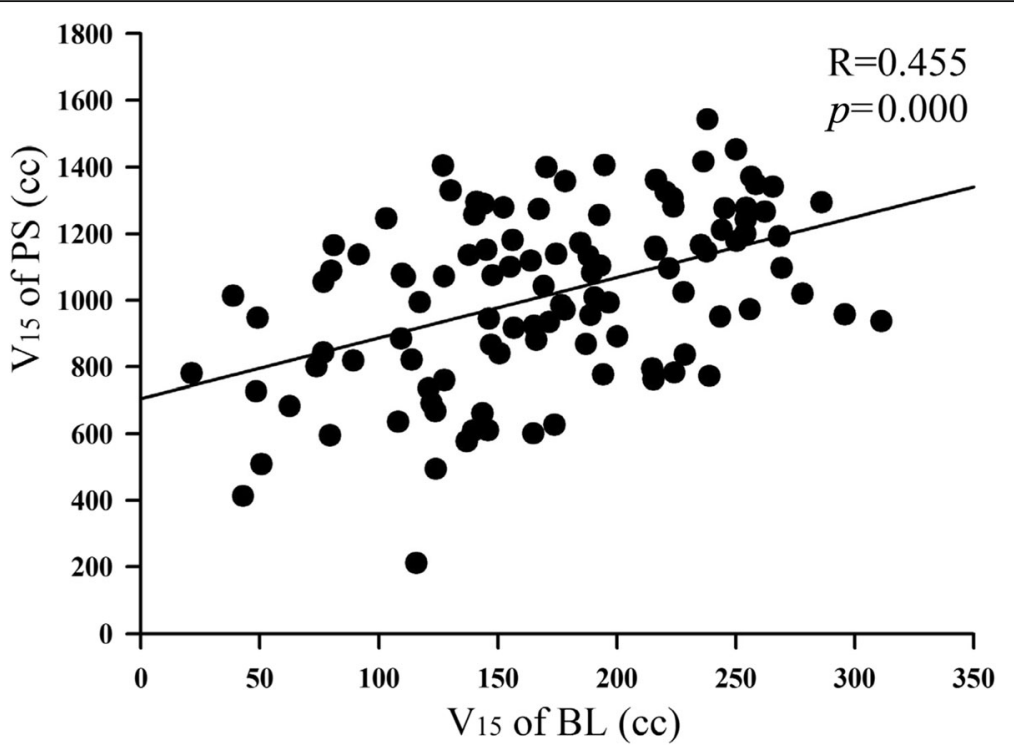

Fig. 3 Correlation of $V_{15}$ between the PS and BL based on all of the CT scans

replaces the $\mathrm{BL}$ for dose constraints with clinical significance.

In this study, we first evaluated small bowel movement during treatment. Our results showed that variations of all BL's dose-volume were larger than 28\%, while most of PS were below $20 \%\left(\mathrm{~V}_{5-40}\right)$, and variations in prone position was significantly lower than in the supine position (Fig. 2). Kvinnsland et al. studied the dose volume changes in the small bowel through 6 to 8 repeated CT scans in 10 patients with bladder cancer. Their results showed that the relative standard deviations of $\mathrm{V}_{30.8}, \mathrm{~V}_{49.5}$, and $\mathrm{V}_{53.5}$ were 20,24 , and $26 \%$ respectively. The authors believed that small

Table 4 Comparison of the small bowel dose-volume and NTCP between prone and supine patients

\begin{tabular}{lllll}
\hline Variable & Supine position & Prone position & $T$ & $p$ \\
\hline$V_{5}(\mathrm{cc})$ & $361.0 \pm 113.2$ & $208.0 \pm 62.0$ & 3.73 & 0.003 \\
$V_{10}(\mathrm{cc})$ & $262.4 \pm 78.5$ & $191.4 \pm 58.2$ & 3.64 & 0.003 \\
$V_{15}(\mathrm{cc})$ & $176.6 \pm 47.2$ & $160.0 \pm 51.1$ & 1.84 & 0.092 \\
$V_{20}(\mathrm{cc})$ & $139.2 \pm 44.7$ & $134.7 \pm 49.6$ & 0.24 & 0.811 \\
$V_{25}(\mathrm{cc})$ & $112.8 \pm 41.9$ & $110.3 \pm 45.0$ & -0.28 & 0.777 \\
$V_{30}(\mathrm{cc})$ & $86.8 \pm 38.6$ & $76.6 \pm 37.9$ & -0.28 & 0.779 \\
$V_{35}(\mathrm{cc})$ & $67.5 \pm 34.1$ & $60.3 \pm 32.4$ & -0.02 & 0.980 \\
$V_{40}(\mathrm{cc})$ & $52.4 \pm 29.2$ & $47.5 \pm 28.9$ & 0.06 & 0.953 \\
$V_{45}(\mathrm{cc})$ & $38.8 \pm 24.7$ & $36.6 \pm 24.4$ & 0.18 & 0.856 \\
$V_{50}(\mathrm{cc})$ & $21.3 \pm 20.4$ & $23.0 \pm 16.8$ & 0.24 & 0.813 \\
D $_{\max }(\mathrm{cGy})$ & $5341 \pm 28$ & $5341 \pm 29$ & 0.01 & 0.989 \\
NTCP $_{C}(\%)$ & $4.9 \pm 2.9$ & $2.3 \pm 1.6$ & 2.14 & 0.055 \\
NTCP $_{A}(\%)$ & $58.3 \pm 7.1$ & $55.7 \pm 9.8$ & 1.74 & 0.109 \\
\hline
\end{tabular}

bowel dose limitations should be carefully considered when variations in the irradiation volume exceeded $20 \%$ [27]. Sanguineti et al. confirmed small bowel movement during prostate cancer radiotherapy by continuous CT scanning. The results showed that $280 \mathrm{cc}$ of the small bowel completely changed position on planned CT, while only $20 \%$ remained in its original position [28].

The movement characteristics of the small bowel make it necessary to explore the reliability of the PS dose limit method for small bowel sparing in IMRT. We used $\mathrm{V}_{15}<275 \mathrm{cc}$ and $\mathrm{D}_{\max } \leqq 54$ Gy as the safety standard for small bowel during treatment, our results showed that majority of $D_{\max }$ and $V_{15}$ were meet the safety standard, and indicating that the PS limit method was feasible for small bowel sparing.

Although the recommended dose constraint from Robyn B was used in this study [16], there are slightly different research methods and irradiation techniques between the two. The PS dose and small bowel with PTV 45 Gy followed by tumour 5.4 Gy boost in the literature may be lower than the present study (50 Gy PTV dose), while the four-field conformal technique may lead to a higher dose than the IMRT technique used in this study. $\mathrm{V}_{15}<830 \mathrm{cc}$ used as the dose constraint in this study was relatively strict, approximately half of the plans (13/24) exceeded this standard, and the median value exceeded $10.71 \%$. But even so, our results showed that the small bowel dose-volume could be further reduced by strictly limiting the PS dose, so it is appropriate to use $\mathrm{V}_{15}<830 \mathrm{cc}$ as the dose constraint.

Patients with prior abdominal surgery are tend to experience greater rates of radiation-induced enteritis 

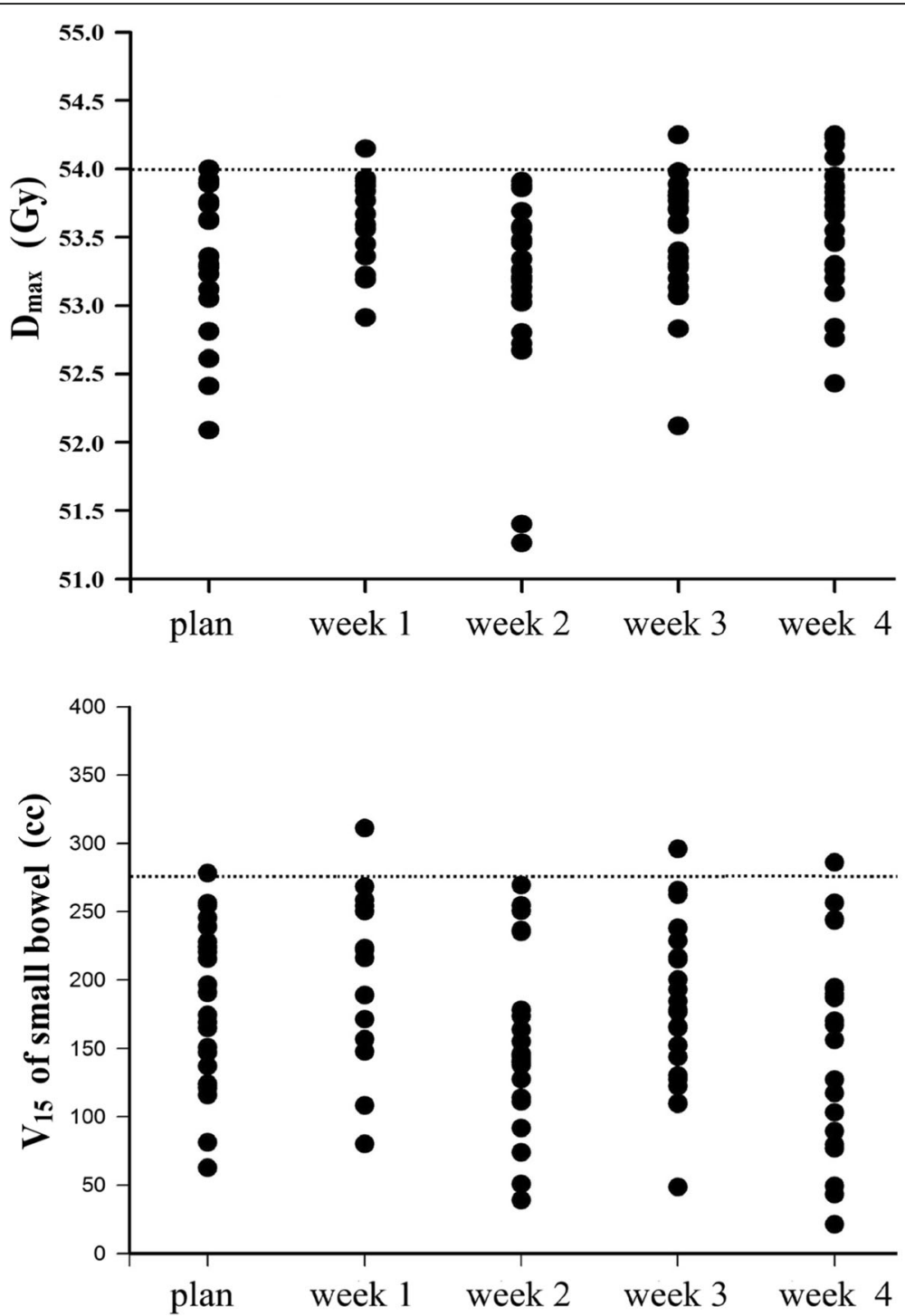

Fig. 4 Safety assessment of the small bowel in 24 patients with rectal cancer during treatment. The top and bottom pictures are the $D_{\max }$ and $V_{15}$ estimation, respectively

[29], it may also affect the movement of small bowel during treatment. Because neoadjuvant treatment was not fully popularized in our hospital in 2014 and 2015, only 8 patients with neoadjuvant radiotherapy were involved in our study. Among the 8 patients, 3 were supine and 5 were prone position, the mixing of position effects make it difficult to compare the difference of small bowel movement between neoadjuvant and adjuvant radiotherapy patients.

Regarding the upper boundary of the PS and BL, Robyn B defined $1.5 \mathrm{~cm}$ above the PTV [16] while our study used RTOG of $1.0 \mathrm{~cm}$ [17]. There was no substantial difference between $1.0 \mathrm{~cm}$ and $1.5 \mathrm{~cm}$ because coplanar IMRT technology and absolute volume (cc) evaluation were used in this study. An upper boundary larger than $1 \mathrm{~cm}$ above the PTV should be adopted when using non-coplanar irradiation, while $2-5 \mathrm{~cm}$ should be used for tomotherapy [17].

The supine and prone position with a belly board are common therapeutic positions in IMRT for rectal cancer. Our results showed that dose-volume, NTCP and their variations of small bowel were less in prone than supine position (Fig.2 and Table 4), consistent with previous studies [30-33]. Nevertheless, the design reproducibility and target dose coverage were significantly superior in the supine position. Some studies reported that patient positioning in RT for rectal cancer patients may therefore be selected based on other factors such as the most comfortable position for the patients [33, 34]. 
The PS defined in this study included the small bowel, colon, and space between the intestines. The PS used objectively in IMRT planning can reduce the overall PS dose volume, making it easier to reduce the small bowel dose. It reduces high dose irradiation caused by small intestinal movement during treatment, so it has an advantage over the BL limit. Which uses only the small bowel as the objective function. Further research showed that there was a significant correlation of $\mathrm{V}_{15}$ between the PS and $\mathrm{BL}$ (Fig. 3, $\mathrm{R}=0.455, p=0.000$ ), indicating that the PS can replace the $\mathrm{BL}$ as the objective function of the dose constraint in IMRT planning. However, when using the PS limit, attention should be paid to the occurrence of PS dose hotspots in the absence of BL evaluation, especially when the dose limits are more stringent, and dose hotspots in PS must be evaluated and avoided to prevent excessive small bowel irradiation.

Our study may be too broad in showing the amplitude of small bowel movement, because involving neoadjuvant and adjuvant therapy patients, which may be a limitation in our study. On the other hand, $V_{15}$ as the primary dose-volume evaluation methods in this study was from conformal radiotherapy era, whether it is suitable for IMRT needs further clinical verification. Recent research shows that the moderate to high dose $\left(\mathrm{V}_{20-40}\right)$ trends toward being significantly associated with acute toxity of small bowel in IMRT $[35,36]$.

\section{Conclusions}

Our findings demonstrated that small bowel motion may lead to uncertainties in its dose volume and NTCP assessment during IMRT for rectal cancer. The BL movements were significantly greater than the PS and significantly less in the prone position than in the supine position. It is feasible to use the PS instead of the $\mathrm{BL}$ limit to spare the small bowel. $\mathrm{V}_{15}<830 \mathrm{cc}$ can be used as the dose constraint standard.

\footnotetext{
Abbreviations

PS: Peritoneal space; BL: Bowel loops; IMRT: Intensity-modulated radiotherapy; NTCP: Normal tissue complication probability; QUANTEC: Quantitative Analysis of Normal Tissue Effects in the Clinic; CT: Computed Tomography; RTOG: Radiation Therapy Oncology Group; PTV: Planning target volume; MLCs: Multi-leave collimators; NCCN: The National Comprehensive Cancer Network; CTV: Clinical target volume; $D_{\text {max }}$ : Maximum dose; NTCP: Chronic complication probability of the small bowel; NTCP A: Acute complication probability of the small bowel; $V_{30.8}, V_{49.5}$, $V_{53.5}$ : Volume receiving at least $30.8 \mathrm{~Gy}, 49.5 \mathrm{~Gy}, 53.5 \mathrm{~Gy} ; \mathrm{V}_{10}, \mathrm{~V}_{15}, \mathrm{~V}_{30}$ : Volume receiving at least $10 \mathrm{~Gy}, 15 \mathrm{~Gy}, 30 \mathrm{~Gy}$
}

\section{Acknowledgements}

Not applicable.

\section{Authors' contributions}

$\mathrm{SL}$, and YG: project conception and design, data collection, assembly, analysis and interpretation, manuscript writing. $Y Y$, and QG: data collection and assembly. JQ, and $Y T$ revised and approved the final manuscript. All authors read and approved the final manuscript.

\section{Funding}

Jiangsu Provincial Medical Innovation Team (CXDT-37) and Jiangsu Provincial Key Research and Development Programme (BE2018657).

\section{Availability of data and materials}

The datasets used and analyzed during the current study are available from the corresponding author on reasonable request.

\section{Ethics approval and consent to participate}

The study was approved by the ethics committee of The Second Affiliated Hospital of Soochow University (2014047).

\section{Consent for publication}

Not applicable.

\section{Competing interests}

The authors declare that they have no competing interests.

\section{Author details}

${ }^{1}$ Department of Radiotherapy \& Oncology, Second Affiliated Hospital of Soochow University, Institute of Radiotherapy and Oncology, Soochow University, Suzhou Key Laboratory for Radiation Oncology, Suzhou 215004, China. ${ }^{2}$ Department of Oncology, Zhang Jia Gang First Hospital, Suzhou 215004, China. ${ }^{3}$ Department of Radiology, Second Affiliated Hospital of Soochow University, Suzhou 215004, China.

Received: 16 April 2020 Accepted: 20 August 2020

Published online: 01 September 2020

\section{References}

1. Holyoake DLP, Partridge M, Hawkins MA, et al. Systematic review and metaanalysis of small bowel dose-volume and acute toxicity in conventionallyfractionated rectal cancer radiotherapy. Radiother Oncol. 2019;138:38-44.

2. Glimelius B, Tiret E, Cervantes A, Arnold D, ESMO Guidelines Working Group. Rectal cancer: ESMO clinical practice guidelines for diagnosis, treatment and follow-up. Ann Oncol. 2013;24(Suppl 6):vi81-8.

3. Sebag-Montefiore D, Stephens RJ, Steele R, Monson J, Grieve R, Khanna S, et al. Preoperative radiotherapy versus selective postoperative chemoradiotherapy in patients with rectal cancer (MRC CR07 and NCIC-CTG C016): a multicentre, randomised trial. Lancet. 2009;373(9666):811-20.

4. Sauer R, Becker H, Hohenberger W, Rödel C, Wittekind C, Fietkau R, et al. Preoperative versus postoperative chemoradiotherapy for rectal cancer. N Engl J Med. 2004;351(17):1731-40.

5. Bosset JF, Collette L, Calais G, Mineur L, Maingon P, Radosevic-Jelic L, et al. Chemotherapy with preoperative radiotherapy in rectal cancer. $\mathrm{N}$ Engl J Med. 2006:355(11):1114-23.

6. Sauer R, Liersch T, Merkel S, Fietkau R, Hohenberger W, Hess C, et al. Preoperative versus postoperative chemoradiotherapy for locally advanced rectal cancer: results of the German CAO/ARO/AIO-94 randomized phase III trial after a median follow-up of 11 years. J Clin Oncol. 2012;30(16):1926-33.

7. Braendengen $M$, Tveit KM, Berglund A, Birkemeyer E, Frykholm G, Påhlman $L$, et al. Randomized phase III study comparing preoperative radiotherapy with chemoradiotherapy in nonresectable rectal cancer. J Clin Oncol. 2008; 26(22):3687-94.

8. Bruheim K, Guren MG, Skovlund E, Hjermstad MJ, Dahl O, Frykholm G, et al. Late side effects and quality of life after radiotherapy for rectal cancer. Int J Radiat Oncol Biol Phys. 2010;76(4):1005-11.

9. Jadon R, Higgins E, Hanna L, Evans M, Coles B, Staffurth J. A systematic review of dose volume predictors and constraints for late bowel toxicity following pelvic radiotherapy. Radiat Oncol. 2019;14(1):57.

10. Gandhi AK, Sharma DN, Rath GK, Julka PK, Subramani V, Sharma S, et al. Early clinical outcomes and toxicity of intensity modulated versus conventional pelvic radiation therapy for locally advanced cervix carcinoma: a prospective randomized study. Int J Radiat Oncol Biol Phys. 2013;87(3): 542-8.

11. Robertson JM, Lockman D, Yan D, Wallace M. The dose volume relationship of small bowel irradiation and acute grade 3 diarrhea during chemoradiotherapy for rectal cancer. Int J Radiat Oncol Biol Phys. 2008; 70(2):413-8.

12. Reis T, Khazzaka E, Welzel G, Wenz F, Hofheinz RD, Mai S. Acute small-bowel toxicity during neoadjuvant combined radiochemotherapy in locally 
advanced rectal cancer: determination of optimal dose volume cut-off value predicting grade 2-3 diarrhoea. Radiat Oncol. 2015;10(1):30.

13. Kavanagh BD, Pan CC, Dawson LA, Das SK, Li XA, Haken RKT, et al. Radiation dose volume effects in the stomach and small bowel. Int I Radiat Oncol Biol Phys. 2010;76(3 Suppl):S101-7.

14. Banerjee R, Chakraborty S, Nygren I, Sinha R. Small bowel dose parameters predicting grade $\geq 3$ acute toxicity in rectal Cancer patients treated with neoadjuvant Chemoradiation: an independent validation study comparing peritoneal cavity versus small bowel loop contouring techniques. Int J Radiat Oncol Biol Phys. 2013;85(5):1225-31.

15. Chi A, Nguyen NP, Xu J, Ji M, Tang J, Jin J, et al. Correlation of three different approaches of small bowel delineation and acute lower gastrointestinal toxicity in adjuvant pelvic intensity-modulated radiation therapy for endometrial cancer. Technol Cancer Res T. 2012;1 (4):353-9.

16. Robyn B, Santam C, lan N, Richie S. Small bowel dose parameters predicting grade $\geq 3$ acute toxicity in rectal Cancer patients treated with neoadjuvant Chemoradiation: an independent validation study comparing peritoneal cavity versus small bowel loop contouring techniques. Int J Radiat Oncol Biol Phys. 2012;85(5):1225-31

17. Gay HA, H Joseph B, Elizabeth O, Walter RB, Issam EN, Rawan A, et al. Pelvic normal tissue contouring guidelines for radiation therapy: a radiation therapy oncology group consensus panel atlas. Int J Radiat Oncol Biol Phys. 2012;83(3):e353-62.

18. Myerson RJ, Garofalo MC, El Naqa I, Abrams RA, Apte A, Bosch WR, et al. Elective clinical target volumes for conformal therapy in anorectal cancer: a radiation therapy oncology group consensus panel contouring atlas. Int J Radiat Oncol Biol Phys. 2009;74(3):824-30.

19. Reyngold M, Niland J, Ter VA, Milne D, Milne BS, Cohen SJ, et al. Neoadjuvant radiotherapy use in locally advanced rectal cancer at NCCN member institutions. J Natl Compr Cancer Netw. 2014;12(2):235-43.

20. Nuyttens J, Robertson J, Yan D, Martinez A. The influence of small bowel motion on both a conventional three-field and intensity modulated radiation therapy (IMRT) for rectal cancer. Cancer Radiother. 2004;8(5):297-304

21. Webb $S$, Nahum AE. A model for calculating tumor control probability in radiotherapy including the effects of inhomogeneous disributions of dose and clonogenic cell density. Phys Med Biol. 1993;38(6):653-66.

22. Burman C, Kutcher GJ, Emami B, Goitein M. Fitting of normal tissue tolerance data to an analytic function. Int J Radiat Oncol Biol Phys. 1991; 21(1):123-35.

23. Lyman JT, Wolbarst AB. Optimization of radiation therapy III: a method of assessing complication probabilities from dose volume histograms. Int J Radiat Oncol Biol Phys. 1987;13(1):103-9.

24. Cella L, Ciscognetti N, Martin G, Liuzzi R, Punzo G, Solla R, et al. Preoperative radiation treatment for rectal Cancer: comparison of target coverage and small bowel NTCP in conventional vs. 3D-conformal planning. Med Dosim. 2009;34(1):75-81.

25. Tho LM, Glegg M, Paterson J, Yap C, MacLeod A, McCabe M, et al. Acute small bowel toxicity and preoperative chemoradiotherapy for rectal cancer: investigating dose volume relationships and role for inverse planning. Int J Radiat Oncol Biol Phys. 2006;66(2):505-13.

26. Tai Y. Physiology (textbooks for colleges and universities in China, for clinical medicine of 8 years and 7 years). Beijing: People's HealthPublishing House; 2011.

27. Kvinnsland Y, Muren LP. The impact of organ motion on intestine doses and complication probabilities in radiotherapy of bladder cancer. Radiother Oncol. 2005;76(1):43-7.

28. Sanguineti G, Little M, Endres EJ, Sormani MP, Parker BC. Comparison of three strategies to delineate the bowel for whole pelvis IMRT of prostate cancer. Radiother Oncol. 2008;88(1):95-101.

29. Huang EY, Sung CC, Ko SF, Wang CJ, Yang KD. The different volume effects of small-bowel toxicity during pelvic irradiation between gynecologic patients with and without abdominal surgery: a prospective study with computed tomography-based dosimetry. Int I Radiat Oncol Biol Phys. 2007; 69(3):732-9.

30. Kószó R, Varga L, Fodor E, Kahán Z, Cserháti A, Hideghéty K, et al. Prone positioning on a belly board decreases rectal and bowel doses in pelvic intensity-modulated radiation therapy (IMRT) for prostate Cancer. Pathol Oncol Res. 2019;25(3):995-1002.

31. Koeck J, Kromer K, Lohr F, Baack T, Siebenlist K, Mai S, et al. Small bowel protection in IMRT for rectal cancer. Strahlenther Onkol. 2017;193(7):578-88.
32. Sawayanagi S, Yamashita H, Ogita M, Kiritoshi T, Nakamoto T, Abe O, et al. Volumetric and dosimetric comparison of organs at risk between the prone and supine positions in postoperative radiotherapy for prostate cancer. Radiat Oncol. 2018;13(1):70.

33. Yang Y, Cai S, Zhao T, Peng Q, Qian J, Tian Y. Effect of prone and supine treatment positions for postoperative treatment of rectal cancer on target dose coverage and small bowel sparing using intensity-modulated radiation therapy. Transl Cancer Res. 2019;9(2):491-9.

34. Frøseth TC, Strickert T, Solli KS, Salvesen O, Frykholm G, Reidunsdatter JR. A randomized study of the effect of patient positioning on setup reproducibility and dose distribution to organs at risk in radiotherapy of rectal cancer patients. Radiat Oncol. 2015;10(1):217.

35. Olsen J, Moughan J, Myerson R, Abitbol A, Doncals DE, Johnson D, et al. Predictors of radiotherapy-related GI toxicity from anal Cancer DP-IMRT: secondary analysis of NRG oncology RTOG 0529. Int J Radiat Oncol Biol Phys. 2017;98(2):400-8.

36. Sini C, Noris Chiorda B, Gabriele P, Sanguineti G, Morlino S, Badenchini F, et al. Patient-reported intestinal toxicity from whole pelvis intensitymodulated radiotherapy: first quantification of bowel dose-volume effects. Radiother Oncol. 2017;124(2):269-301.

\section{Publisher's Note}

Springer Nature remains neutral with regard to jurisdictional claims in published maps and institutional affiliations.
Ready to submit your research? Choose BMC and benefit from:

- fast, convenient online submission

- thorough peer review by experienced researchers in your field

- rapid publication on acceptance

- support for research data, including large and complex data types

- gold Open Access which fosters wider collaboration and increased citations

- maximum visibility for your research: over $100 \mathrm{M}$ website views per year

At BMC, research is always in progress.

Learn more biomedcentral.com/submissions 